\title{
Potential of used frying oil in paving material: solution to environmental pollution problem
}

\author{
Dimple Singh-Ackbarali ${ }^{1}$ (D) Rean Maharaj ${ }^{1} \cdot$ Nazim Mohamed $^{1}$. \\ Vitra Ramjattan-Harry ${ }^{1}$
}

Received: 27 May 2016 / Accepted: 9 March 2017 /Published online: 28 March 2017

(C) The Author(s) 2017. This article is published with open access at Springerlink.com

\begin{abstract}
The improper disposal of used frying oil (UFO) presents numerous ecological, environmental and municipal problems. Of great concern is the resultant blockage of municipal drainage systems and water treatment facilities, harm to wildlife when they become coated in it and detriment to aquatic life and ecosystems due to the depletion of the oxygen content in water bodies such as rivers and lakes that have become contaminated. Statistics show that in Trinidad and Tobago, in excess of one million liters of used cooking oil is collected annually from various restaurant chains. This paper investigated the potential of using UFO as a performance enhancing additive for road paving applications utilizing Trinidad Lake Asphalt (TLA) and Trinidad Petroleum Bitumen (TPB) as a mitigation strategy for improper UFO disposal. Modified blends containing various additions of UFO (2-10\% wt) were prepared for the TLA and TPB asphaltic binders. Results demonstrated in terms of stiffness, increasing the dosage of UFO in TLA and TPB base binders resulted in a gradual decrease in stiffness ( $\mathrm{G}^{*}$ value decreased). In terms of elasticity, increasing the dosage of the UFO additive in TLA resulted in a general decrease in the elasticity of the blends indicated by an increase in phase angle or phase lag $(\delta)$. Increasing dosages of the UFO additive in TPB resulted in a significant decrease in $\delta$ where the most elastic blend was at the $6 \%$ UFO level. TLA and UFO-TLA modified blends exhibited significantly lower values of $\delta$ and higher values of $G^{*}$ confirming the superiority of the TLA material. Incorporation
\end{abstract}

Responsible editor: Philippe Garrigues

Dimple Singh-Ackbarali

dimple.singh@utt.edu.tt

1 The University of Trinidad and Tobago, O'Meara Industrial Park, 74-98 Churchill Roosevelt Highway, Arima, Trinidad and Tobago of the UFO in the blends led to a decrease in the rutting resistance and increase in the fatigue cracking resistance (decrease in $G^{*} / \sin \delta$ and $G^{*} \sin \delta$, respectively). This study highlighted the potential for the reuse of UFO as an asphalt modifier capable of producing customized UFO modified asphaltic blends for special applications and confirms its feasibility as an environmentally attractive means of reusing the waste/hazardous UFO material locally.

Keywords Used frying oil · Trinidad Lake Asphalt · Trinidad Petroleum Bitumen $\cdot$ Rutting resistance $\cdot$ Fatigue cracking

\section{Introduction}

\section{The environmental problem}

Frying oil is vegetable and animal oil that is used to fry food at high temperatures by the food industry, restaurants/food service establishments, and homes. The used frying oil (UFO) generated by these activities has become a major environmental and ecological issue, especially since it is usually indiscriminately discarded after use, into municipal landfills or poured down drains without any treatment (Patil et al. 2012, Zhang et al. 2012, Dias et al. 2014).

Petroleum oils, vegetable oils, and animal fats share common physical properties and produce similar environmental effects as outlined by literature (EPA 2015, Rodewald 2015). They include:

- Suffocation of animals and plants that have been coated with oil

- Eutrophication due to micro-organisms, phytoplankton, and algae which use the UFO as a food source 
- Reduction in dissolved oxygen content and the death of aquatic plants and animals as a result of the existence of the layer of oil on water bodies which prevents sunlight from getting to aquatic plants stifling photosynthesis

- Rancid odor production

- Clogging of drainage systems and water treatment plants

- Isolation of soil from air and water, killing the earth worms, and bacteria necessary for regeneration of plants

- Proliferation of rats and vermin that feed on the solidified waste cooking oil which creates a pest control problem or health hazard.

In Trinidad and Tobago, the amended Water Pollution Rules (WASA 2006) targets commercial business activities using cooking oil such as restaurants, food service companies, and even households where these entities are required by law to register with the Environmental Management Authority (EMA). However according to an interview with a managing director of a company that collects and recycles used cooking oil, the manager stated that the laws on cooking oil disposal is not enforced as it is either frozen and thrown away or poured down the drain.

Information collected in 2010 by the Trinidad and Tobago Central Statistical Office reported that there were 317 food and drink processing establishments and 297 hotel and guest establishments in the country. A study found that a popular internationally based fried chicken fast food outlet used approximately $151.4 \mathrm{~L}$ of oil per week and when this is translated to all of its 52 outlets; over 409,000 L of UFO can be collected annually from this one franchise alone (John and Seetahal 2008). It is estimated that commercial establishments would use $30 \%$ of the available edible oil, 55,315 L of edible oil a day (Wyse-Mason and Beckles 2012). The remaining $70 \%$ of the consumed edible oil are utilized by residential households that are not required to have disposal facilities such as oil separators, grease traps, waste water sumps, or have their used cooking oil collected by recycling or treatment and disposal companies. This allows a significant quantity of UFO to be disposed of down the sink and drain, onto the ground, and into the garbage. Currently, the UFO generated commercially from Trinidad restaurants is contracted to one company who indicated that they collect up to one million liters of UFO annually.

\section{Possible solutions}

Used oil is the "single largest environmentally hazardous recyclable material" (MARRC 2001) and a spill of used oil as small as $1 \mathrm{~L}$ can potentially contaminate a million liters of fresh water. The recycling of waste oil is becoming a viable alternative in mitigating the associated environmental and ecological problems (El-Fadel and Khoury 2001). However, developing countries struggle to properly manage their used oil due to inadequate collection services and limited utilization of recycling. Third world countries are lagging behind in this regard as they have low awareness regarding recycling of waste materials, not yet developed effective legislation, and have not yet selected lead agencies responsible for rules, regulations, and enforcement legislation (Batayne et al. 2008, Kahn et al. 2009). Progress is being made in this region, however, as the Basel Convention Regional Centre for Training and Technology Transfer for the Caribbean Region (BCRCCaribbean) has a new central focus which shifts away from the strict prohibition of the movement of hazardous wastes from one party to another, towards the recognition of waste as a resource which can stimulate economic development and create new employment opportunities, more so among civil society groups and small business entrepreneurs. This new focus encourages waste prevention and minimization at source and waste recovery, reuse, and recycling as downstream value added components of the waste stream (Basel Convention Region Business Plan 2012). In order for a reduction in negative impacts of improper disposal of UFO in Trinidad and Tobago the following must be done:

- Update national inventory of use and disposal

- Review policy and enable legislation to facilitate waste oil collection, re-refining, disposal and destruction.

- Conduct strategic assessment of appropriate technologies that can be applied

- Develop pilot project with private sector investors

- Review fuel subsidies in Trinidad and Tobago so that local market will be inviting to the use of alternative fuel.

Many researchers have studied the potential use of recycled UFO by integration into the food chain through animal feeds, production of soaps, or conversion to biodiesel; however, limited information exist on its use of UFO as an additive in asphalt pavement binders (Bronislaw 2014, Deba et al. 2015, Panadare and Rathod 2015).

\section{Challenges with past solutions}

Integrating UFO into the food chain through animal feed, can be a potential cause of human health problems as there is some evidence that highly oxidized fats formed during frying where oils are exposed to high temperatures in the presence of atmospheric oxygen, may have carcinogenic properties (Chang and Peterson 1978, Azpilicueta and Remirez 1991, Costa Neto et al. 2000, Panadare and Rathod 2015). The use of waste or used fats and oils in animal feedstock as an additive can also be problematic as when it becomes rancid, it imparts an objectionable odor and decreases palatability of the feed. Additionally, when excess fat or oil exceeds $6 \%$ of the feeds dry matter, inhibition of fiber digestion in rumens can occur (Engstrom et al. 1994, Panadare and Rathod 2015). 
Digestive disturbances, diarrhea, and reduced feed intake may occur if excessive levels of fat are fed to animals. There are several positives when looking at UFO as a fuel source for biodiesel (Sunde et al. 2011, Thamsiriroj and Murphy 2011, Bronislaw 2014) however, before the UFO can be used in saponification and biodiesel production, investments have to be made to pre-treat the waste material via filtration and esterification to remove any free fatty acids (Chang and Peterson 1978, Bronislaw 2014). While pre-treatment for the UFO to be converted to biodiesel may not be expensive, the cost of converting a diesel engine to run on UFO can cost up to TT\$15000.00 (Trinidad and Tobago Newsday 2010), which may be a deterrent for citizens/individuals.

\section{Background and new proposed solution}

Asphalts and bitumen are both used together with mineral aggregates to construct roads/pavements. The performance of these road pavements depend on the properties of the asphalt and the bitumen which are the only deformable components in the mixture. Both these systems have thermal susceptibilities and can become deformed due to weathering, moisture damage, heavy traffic, or embrittlement due to the chemical oxidation of functional groups within the asphalt. These limitations can be overcome as their performance characteristics significantly modified by modification with polymeric materials (Zhu et al. 2014, Maynard et al. 2015). It has been reported that polymer modified asphalt can increase the shelf life of pavements by up to 10 years (Dwyer and Betts 2011, Boyer 2013). The blending of recycled asphalt with UFO has been shown to improve the performance qualities of the resulting blends as the fatty acids present in UFO has been shown to act as cohesive agent, reducing the high viscosity of the aged, recycled binders, facilitating homogenous mixing and reducing surface tension of the aggregate and coated binder, when integrated with new pavement materials (Huh 2012). Other past evaluations of binder performance (Asli et al. 2012, Zargar et al. 2012) showed that a 3-4\% by weight addition of the UFO gave similar viscosity results compared to the original bitumen material. It was also reported that the used of vegetable oil decreases the stiffness of the aging mixture (Bailey and Philips 2010).

Despite the existence of studies using other asphaltic binders from other sources, the influence of polymeric additives on the rheological properties of Trinidad asphaltic materials cannot be generalized and must be independently investigated as a clear relationship between the differences in the quality of asphalt (different compositions) from different sources and the resulting performance qualities of the binders exist; asphaltic materials with the same specifications can often produce pavements of varying physical properties, performance, and serviceability (Oyenkunle 2006, Oyenkunle 2007, Mohamed et al. 2016). TLA is an asphaltic material of unique composition containing significantly higher asphaltene content compared to other refinery bitumen such as TPB. TLA contains kaolinitic clay not present in TPB and other refinery bitumen. These compositional differences have been shown to influence the flow, colloidal characteristics, and rheological properties of asphaltic systems which ultimately influences their performance attributes. A literature survey shows that previous studies measuring the influence of UFO on the rheological properties of the asphaltic materials TLA and TPB, indigenous to Trinidad and Tobago have proven to be limited.

Despite the reported enhancement of asphaltic materials modified with polymeric additives, there are some associated difficulties. Polymer modified asphaltic materials have been linked to increased amounts of polycyclic aromatic hydrocarbons (PAHs) being leached into storm water and contaminating water bodies. PAHs consist of over a hundred organic compounds with two or more aromatic rings that occur together as mixtures. They can be concentrated by incomplete burning of carbon-containing material; sources include tyres and crumbling asphalt. Road pavement material and car park sealants can contribute significant amounts of PAHs to water ways via storm water which can be toxic to aquatic animals (Wright et al. 2009). A 2006 evaluation of PAHS in frying oils found that both before and after frying, the benzo-apyrene concentration in edible oils ranged from trace to $0.7 \mathrm{ppb}$, well below the $2 \mathrm{ppb}$ limit for PAHs in foods recently proposed by the European Community (Purcaro et al. 2006). Research showed that crumb rubber samples analyzed had high levels of PAHs and Zinc (Marsili et al. 2015).

This paper seeks to fill the gap of research investigating the influence of UFO on the rheological properties of TLA and TPB asphaltic materials indigenous to Trinidad and Tobago, and hence assess its potential as an environmentally attractive means of reusing the waste/hazardous UFO material locally.

\section{Experimental}

\section{Materials sources}

A gallon of used frying oil (UFO) was obtained from a commercial restaurant in South Trinidad. Trinidad Lake Asphalt (TLA) and Trinidad Petroleum Bitumen (TPB) were sourced from the Lake Asphalt Company of Trinidad and Tobago and the Petroleum Company of Trinidad and Tobago Limited, respectively.

\section{Sample preparation}

Aluminum cans of approximately $500 \mathrm{~cm}^{3}$ were filled with 250 $260 \mathrm{~g}$ of asphalt and put in a thermoelectric heater Thermo Scientific Precision (Model 6555) where the temperature was raised to $200{ }^{\circ} \mathrm{C}$. A digital IKA (Model RW20D) high shear mixer was then immersed in the can and set to $3000 \mathrm{rpm}$. The UFO was added gradually while the system was kept at a 
temperature of $200 \pm 1{ }^{\circ} \mathrm{C}$. Each TLA-UFO and TPB-UFO blend was formed from $0,2,4,6,8$, and $10 \%$ of UFO by weight. At the end of mixing, each blend was split into different cans, transferred to a desiccator and stored under static conditions and in an oxygen-free environment. After $24 \mathrm{~h}$ period of curing, the cans were taken out, remixed using high shear mixer, and the molten mixtures were then cast into a ring stamp with $25 \mathrm{~mm}$ diameter and $1 \mathrm{~mm}$ thickness for subsequent rheological testing. Before testing, the samples were cooled at room temperature and stored in a Fisher Isotemp freezer at $-20^{\circ} \mathrm{C}$.

\section{Rheological measurements}

The rheological characterization of the various asphalt blends were studied using an oscillatory dynamic shear rheometer (ATS RheoSystems) operated within the linear domain under strain control. The test geometries were plate to plate (diameters 25 and $1 \mathrm{~mm}$ gap). Viscosity measurements were conducted in the temperature range $40-90{ }^{\circ} \mathrm{C}$ and frequency range was $0.1-15.91 \mathrm{~Hz}$. The analysis was performed under the strain control mode and the complex modulus $\left(G^{*}\right)$ and phase angle $(\delta)$ values at the different oscillating frequencies and temperatures were calculated using the instruments software.

\section{Results and discussion}

The use of measurements using dynamic shear rheometer (DSR) rheological properties of Trinidad asphalt materials at temperatures from high to intermediate values are an important consideration in understanding pavement distress characteristics such as pavement deformation due to rutting and shearing. The understanding and application of this technique is welldocumented by Kim (2009) and has been successfully utilized for the rheological characterization of polymer modified asphaltic materials including the measurement of key performance attributes of fatigue cracking and rutting resistance (Hosein et al. 2013, Maharaj and Maharaj 2015, Maynard et al. 2015).

Deformation in asphalt material consists of three types:

- Instant elastic recoverable strain

- Delayed elastic recoverable strain

- Permanent non-recoverable strain (or viscous flow)

Most critical among these is the permanent nonrecoverable strain or viscous flow parameter which determines the permanent deformation of the traffic asphalt pavement due to repeated loading forces. Table 1 below describes the different parameters that were tested with the DSR, and introduces the characteristics of the material that can be interpreted when analyzing the results.

Figure 1a, b show the changes in complex shear modulus $\left(G^{*}\right)$ at various oscillating load frequencies at $60{ }^{\circ} \mathrm{C}$, as the concentration of the added UFO was increased for TLA and TPB binders, respectively.

A comparison of Fig. 1a, b shows that unmodified TLA and the UFO-TLA blends exhibited higher $G^{*}$ values than TPB and UFO-TPB blends indicating that they are generally stiffer. This observation was consistent with the findings of previous researchers (Hosein et al. 2013, Maharaj et al. 2014, Maynard et al. 2015). The results show that for both the TLA and TPB base binders, as the concentration of the added UFO was increased gradually, the stiffness generally decreased $\left(G^{*}\right.$ value decreased). A similar observation was recorded by Raghavan and Kaler (2001), Borhan et al. (2009), and Singh-Ackbarali and Maharaj (2011), and it has been suggested that the decrease in $G^{*}$ observed can be attributed to an increased solvency of the maltenes present in the asphaltic materials in the fatty acids present in the UFO; softening the intermolecular cross-linkages which resulted in the modified blends having reduced ability to withstand elongation. When aggregate is added to these UFO modified asphaltic blends, it is expected that the mechanical properties of the pavement
Table 1 The different parameters and characteristics that were tested and analyzed using the DSR

\begin{tabular}{ll}
\hline Parameter & Characteristics that can be interpreted \\
\hline Complex shear modulus, $G^{*}$ & $\begin{array}{c}\text { Represents the total resistance of the asphalt/bitumen sample to } \\
\text { deformation (or stiffness) caused by repeated pulses of small angle } \\
\text { oscillations by the plates of the DSR, high values are desirable for a } \\
\text { stiffer material low values are associated with a softer material } \\
\text { Represents the degree of the elasticity of the material, high values are } \\
\text { associated with high viscosity materials, low values are associated } \\
\text { with highly elastic materials resistance } \\
\text { Phase angle or the phase lag, } \delta\end{array}$ \\
Rutting resistance parameter $G^{*} / \sin \delta$ & $\begin{array}{l}\text { Highes values of } G^{*} / \sin \delta \text { will result in higher rutting resistance of } \\
\text { material, lower values of } G^{*} / \sin \delta \text { will result in lower rutting resistance } \\
\text { of the material }\end{array}$ \\
Fatigue cracking parameter $G^{*} \sin \delta$ & $\begin{array}{l}\text { Low values of } G^{*} \sin \delta \text { will result in higher fatigue cracking resistance } \\
\text { of material higher values of } G^{*} \text { in lower fatigue cracking resistance of } \\
\text { the material }\end{array}$ \\
\hline
\end{tabular}




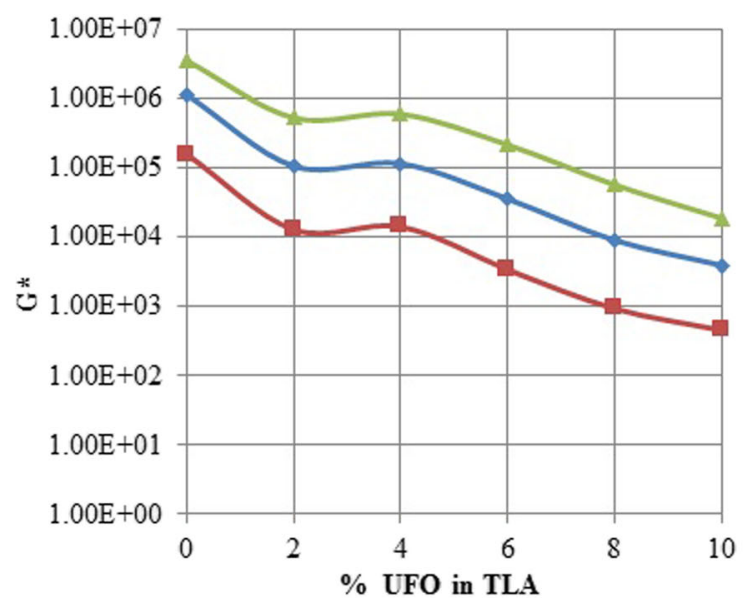

(a)

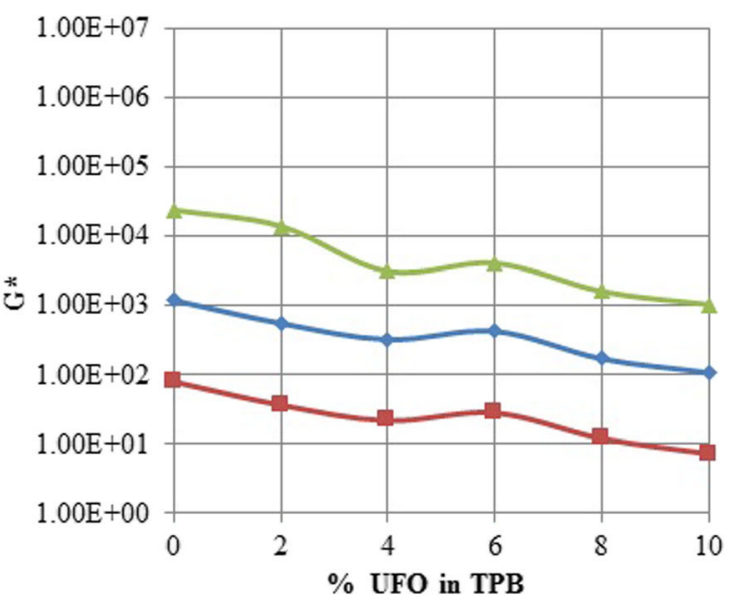

(b)

Fig. 1 The variation of $G^{*}$ with increasing concentration of UFO for TLA and TPB binders at various oscillating load frequencies and at $60{ }^{\circ} \mathrm{C}$

would be improved as the reduced viscosity will result in a reduction in the surface tension between the aggregate and the binder coating, expelling trapped air and increasing interfacial cohesion between the asphaltic binder and aggregate.

Figures $2 \mathrm{a}, \mathrm{b}$ show the variation of the phase angle $\delta$ with increasing concentration of UFO for TLA and TPB, respectively at various oscillating load frequencies and at $60^{\circ} \mathrm{C}$.

The results demonstrated that $\delta$ was generally higher for the TPB and UFO-TPB blends indicating that these blends had lower elasticity. The observation that $\delta$ was almost $90^{\circ}$ for unmodified TPB indicated that the material behaved almost like a viscous liquid. On the other hand, the TLA and UFO-TLA blends had significantly lower values of $\delta$ indicating that these blends were significantly more elastic. The relatively higher values of $G^{*}$ and lower values of $\delta$ observed for the TLA based binder (relatively stiffer and more elastic) offer supporting rheological evidence confirming TLA's world renowned superior qualities

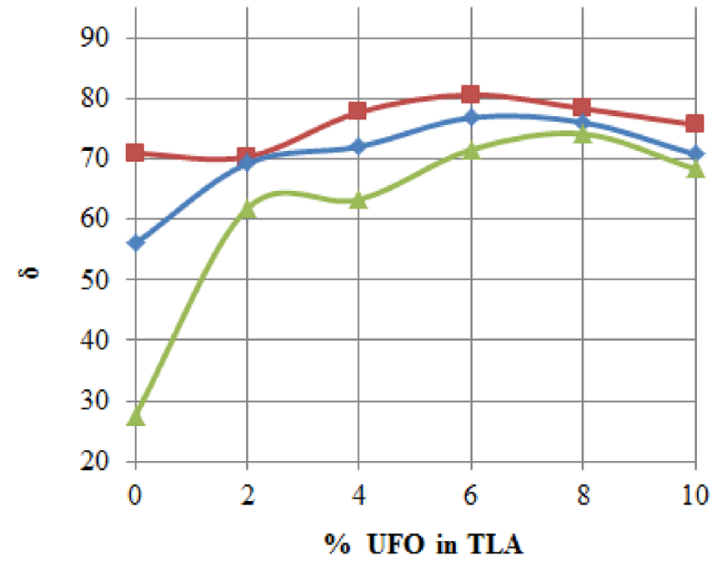

(a) and its consequential use as an additive to improve the properties of other refinery bitumen including TLA (Widyatmoko and Elliott 2008). The effect of increasing the concentration of the UFO additive in TLA resulted in a general decrease in the elasticity of the blends indicated by an increase in $\delta$. The effect of increasing the concentration of the UFO additive in TPB resulted in a significant decrease in $\delta$ at the $6 \%$ UFO level indicating a superior elastic UFO blend.

The variation of the fatigue cracking resistance parameter $\left(G^{*} \sin \delta\right)$ with increasing concentration of UFO in TLA and TPB at various oscillating frequencies at $60{ }^{\circ} \mathrm{C}$ is shown in Fig. 3.

The trend of decreasing $G$ * $\sin \delta$ values as the \% UFO was increased for both TLA and TPB indicates higher fatigue cracking resistance as the UFO component was increased. The TLA and the UFO-TLA blends exhibited higher $G^{*} \sin \delta$ values (lower fatigue cracking resistance values) compared to

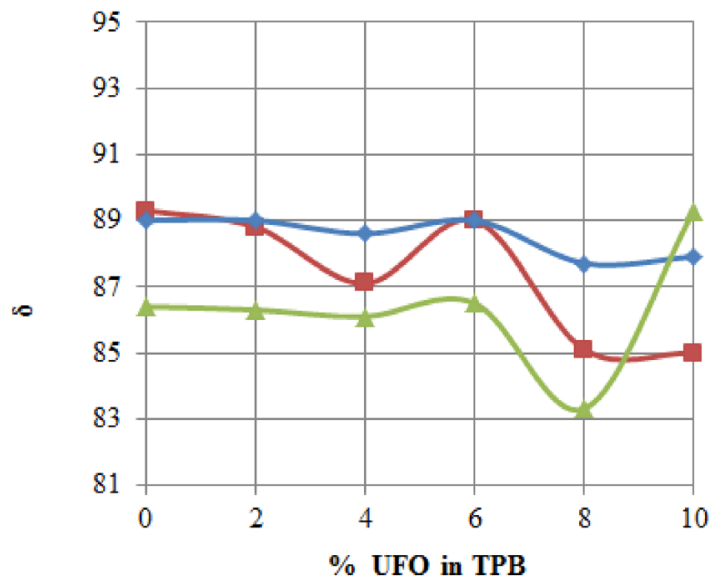

(b)

$-0.1 \mathrm{~Hz} \leadsto-1.59 \mathrm{~Hz} \leftarrow 15.9 \mathrm{~Hz}$

Fig. 2 a, b The variation of $\delta$ with increasing concentration of UFO for TLA and TPB binders at various oscillating load frequencies and at $60{ }^{\circ} \mathrm{C}$ 


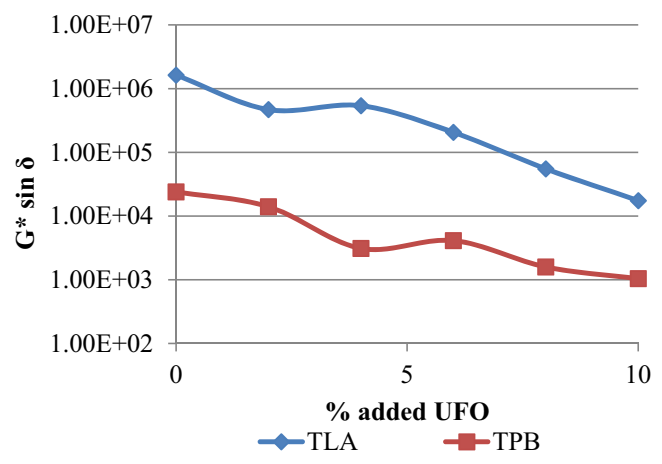

Fig. 3 The variation of the fatigue cracking resistance parameter $\left(G^{*} \sin \delta\right)$ with increasing concentration of UFO in TLA and TPB mix at various oscillating frequencies at $60^{\circ} \mathrm{C}$

TPB and UFO-TPB blends. The variation of the rutting resistance parameter $\left(G^{*} / \sin \delta\right)$ with increasing concentration of UFO in TLA and TPB blends at three oscillating frequencies, respectively are shown in Fig. 4.

The results clearly indicate that the addition of UFO in the TLA and TPB binders resulted in a decrease in the rutting resistance (a decrease in $G^{*} / \sin \delta$ values) of the resulting blends. The unmodified TLA and TPB exhibited superior rutting resistance properties compared to the UFO modified blends. The superiority of the TLA and its UFO-TLA blends was again evident as the $G^{*} / \sin \delta$ (rutting resistance) values were significantly higher than TPB and the UFO-TPB blends.

Differences between the rheological properties observed for the TLA and TPB blends offer supporting evidence for previous studies where it has been shown that the influence of additives on the rheological properties of asphaltic materials from different sources cannot be generalized and must be independently investigated as there exists a clear proven relationship between the differences in the quality of asphalt (different compositions) from different sources and the resulting performance qualities of the binders exist; asphaltic materials with the same specifications can often produce pavements of varying physical properties, performance, and serviceability (Mohamed et al. 2016, 28).

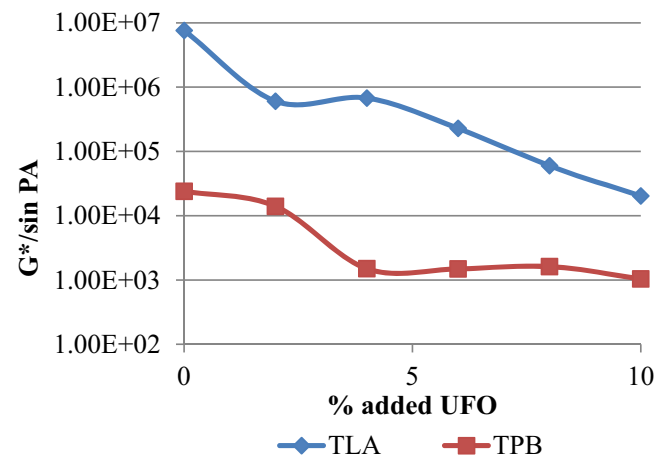

Fig. 4 The variation of the rutting resistance parameter $\left(G^{*} / \sin \delta\right)$ with increasing concentration of UFO in TLA and TPB blends at three oscillating frequencies

\section{Conclusion}

The rheological analysis of modified TLA and TPB blends containing various additions of UFO (2-10\% wt) demonstrated the following:

- In terms of stiffness, increasing the concentration of UFO in the TLA and TPB base binders resulted in a corresponding decrease in stiffness ( $\mathrm{G}^{*}$ value decreased).

- In terms of elasticity, increasing the concentration of the UFO additive in TLA resulted in a general decrease in the elasticity of the blends indicated by an increase in $\delta$. Increasing the concentration of the UFO additive in TPB resulted in a significant decrease in $\delta$ where the most elastic blend was at the $6 \%$ UFO level.

- TLA and UFO-TLA modified blends exhibited significantly lower values of $\delta$ and higher values of $G^{*}$ confirming the superiority of the TLA material.

- Incorporation of the UFO in the blends led to a decrease in the rutting resistance and increase in the fatigue cracking resistance (decrease in $G^{*} / \sin \delta$ and $G^{*} \sin \delta$, respectively).

This study demonstrated the potential reuse of UFO as an asphalt modifier capable of producing customized UFO modified asphaltic blends for special applications. It also demonstrates the feasibility of the reuse strategy as an environmentally attractive means of disposal of the waste/hazardous UFO material locally.

\section{Compliance with ethical standards}

Conflict of interests The authors declare that they have no conflict of interest.

Open Access This article is distributed under the terms of the Creative Commons Attribution 4.0 International License (http:// creativecommons.org/licenses/by/4.0/), which permits unrestricted use, distribution, and reproduction in any medium, provided you give appropriate credit to the original author(s) and the source, provide a link to the Creative Commons license, and indicate if changes were made.

\section{References}

Asli H, Ahmadinia E, Zargar M, Karim MR (2012) Investigation on physical properties of waste cooking oil-rejuvenated bitumen binder. Constr Build Mater 37:398-405

Azpilicueta MCA, Remirez MTM (1991) Study of degradation of olive oils subjected to thermo-oxidation, statistical determination the parameter that best quantifies the degradation. Grasas Aceites 42(1): $22-31$

Bailey HK, Philips P (2010) Asphalt Rejuvenation. US Patent 0034586 A1

Basel Convention Regional Centre for Training and Technology Transfer for the Caribbean (2012) Region Business Plan 2012-2013. http:// www.basel.int/Portals/4/BaselConvention/docs/centers/bussplan/ bp2012-2013/Caribbean.pdf (accessed 22.12.12) 
Batayne MK, Marie I, Asi I (2008) Promoting the use of crumb rubber concrete in developing countries. Waste Manag 28(11):2171-2176

Borhan MN, Suja F, Ismail A, Rahmat R (2009) The effects of used cylinder oil on asphalt mixes. Eur J Sci Res 28(3):398411

Boyer B (2013) Life cycle performance, Asphalt Magazine. http:// asphaltmagazine.com/the-benefits-ofmodified-asphalts (accessed 21.12.2015)

Bronislaw B (2014) Diesel fuel from used frying oil. Sci World J 2014(683272):3. doi:10.1155/2014/683272

Chang SS, Peterson CL (1978) Chemical reactions involved in the deepfat frying of foods. J Am Oil Chem Soc 55:718-727

Costa Neto PR, Rossi L, Zagonel G, Ramos L (2000) Produção de Biocombustível Alternativo ao Óleo Diesel Através da Transesterificação de Óleo de Soja Usado em Frituras. Quim Nov. 23: $531-537$

Deba AA, Tijani HI, Galadima HI, Mienda BS, Deba FA, Zargoun LM (2015) Waste cooking oil: a resourceful waste for lipase catalysed biodiesel production. Int J Sci Res Publ 5(3)

Dias AC, Nunes MI, Ferreira T, Arroja L (2014) Environmental evaluation of valorization options for used cooking oil. Recent advances in environmental science and biomedicine. WSEAS Press, Sofia

Dwyer J, Betts M (2011) Polymer-modified asphalt: Improving our nation's infrastructure. http://www.pitt.edu/ meb137/paper.html (accessed 21.12.2015)

El-Fadel M, Khoury R (2001) Strategies for vehicle waste oil management: a case study. Resour Conserv Recy 33(2):75-91

Engstrom DF, Goonewardene LA, Grimson RE, McKinnon PJ, Stilborn RP, Volek R (1994) Effects of feeding added protein and fat on feedlot performance and carcass quality in large frame steers. Can J Anim Sci 74:547-549

EPA (2015) Emergency Response, Oil Spills Prevention and Preparedness Regulations-Vegetable Oils and Animal Fats. http:// www.epa.gov/emergency-response/vegetable-oils-and-animal-fats, (accessed 22.12.15)

Hosein S, Maharaj C, Maharaj R, Singh-Ackbarali A (2013) The effect of particle size and concentration of crumb rubber on the rutting and fatigue cracking resistance of Trinidad Lake asphalt and petroleum bitumen. Inter J Arts Sci 6(4):321-335

Huh JD (2012) Temperature-Adjusted and Modified Recycled ASCON Composition for Reusing 100\% of Waste ASCON for Road Pavement, and Method for Manufacturing Same. Article ID 20120167802, US Patent 20120167802 A1

John E, Seetahal S (2008) Biofuels versus food production: investigating an energy efficient lab usage policy for Trinidad and Tobago. Presented at Tobago Gas Technology Conference, Lowlands Tobago, 2008

Kahn DJ, Kaseva ME, Mbuligwe SE (2009) Hazardous waste issues in developing countries. Hazard. Waste Manag. Published by EOLSS, 112-123

Kim YR (2009) Modeling of asphalt concrete. Modeling of asphalt binder rheology and its application to modified binders, Chapter (McGrawHill Professional) Access Engineering

Maharaj R, Maharaj C (2015) Physical properties of low density polyethene, polyvinylchloride and used car oil modified Trinidad Lake asphalt. Prog. Rubber Plast. Recy. Technol. 31(3):145-160

Maharaj R, Grierson L, Singh-Ackbarali D, Mohamed N (2014) The influence of waste polyvinyl chloride on the rheological properties of Trinidad Lake Asphalt. Eur J Sci Res 121(1):48-56

MARRC (Manitoba Association for Resource Recovery Corporation) (2001) Dirty oil. Winnipeg. Manitoba, Canada

Marsili L, Coppola D, Bianchi N, Maltese S, Bianchi M, Fossi MC (2015) Release of polycyclic aromatic hydrocarbons and heavy metals from rubber crumb in synthetic turf fields: preliminary hazard assessment for athletes. J Environ Anal Toxicol 5:265

Maynard J, Maharaj C, Maharaj R (2015) The effect of polyethylene terephthalate particle size and concentration on the properties of asphalt and bitumen as an additive. Prog Rubber Plast Recy Technol 31(1):1-24

Mohamed N, Maharaj R, Ramjattan-Harry V (2016) Mechanistic enhancement of asphaltic materials using fly ash. J Appl Sci 16(11): 526-533

Oyenkunle LO (2006) Certain relationships between chemical composition and properties of petroleum asphalts from different origin. Oil Gas Sci Technol 61(3):433-441

Oyenkunle LO (2007) Influence of chemical composition on the physical properties of paving asphalts. Pet Sci Technol 25:1401-1414

Panadare DC, Rathod VK (2015) Applications of waste cooking oil other than biodiesel: a review. Iranian J Chem Eng 12(3)

Patil P, Gude V, Reddy H, Muppaneni T, Deng S (2012) Biodiesel production from waste cooking oil using sulfuric acid and microwave irradiation processes. J Environ Prot 3(1):107-113. doi:10.4236/jep. 2012.31013

Purcaro G, Navas JA, Guardiola F, Conte LS, Moret S (2006) Polycyclic aromatic hydrocarbons in frying oils and snacks. J Food Protect 69(1):199-204

Raghavan SR, Kaler EW (2001) Highly viscoelastic wormlike micellar solutions formed by cationic surfactants with long unsaturated tails. Langmuir 17(2):300-306

Rodewald J (2015) The Surprising negative impacts of vegetable oils and animal fats. Retrieved from http://www.hazardouswasteexperts. com/the-surprising-negative-impacts-of-vegetable-oils-and-animalfats/, (accessed 05.01.2016)

Singh-Ackbarali D, Maharaj R (2011) The viscoelastic properties of Trinidad Lake Asphalt-used engine oil blends. Int J Appl Chem 7(1):1-8

Sunde K, Brekke A, Solberg B (2011) Environmental impacts and costs of hydrotreated vegetable oils, transesterified lipids and woody BTL — a review. Energies 4(6):845-877

Thamsiriroj T, Murphy J (2011) The impact of the life cycle analysis methodology on whetherbiodiesel produced from residues can meet the EU sustainability criteria for biofuel facilities constructed after 2017. Renew Energy 36:50-63

Trinidad and Tobago Central Statistical Office (2010) Pocket Digest. http://www.planning.gov.tt/sites/default/files/content/mediacentre/ documents/, 2016 (accessed 05.01.16)

Trinidad and Tobago Newsday (2010) Eco-friendly truck runs on used cooking oil. http:/www.newsday.co.tt/features/0,117526.html, (accessed on 22.12.2015)

WASA (2006) The Water Pollution Rules 2001 (as amended by the water pollution (amendment) rules). http://www.wasa.gov.tt/WASA EnvironmentalIssues_PollutionRules.html (accessed 09.03.16)

Widyatmoko I, Elliott R (2008) Characteristics of elastomeric and plastomeric binders in contact with natural asphalts. Constr Build Mater 22:239-249

Wright JD, Hunt WF, Burchell MR, Perrin CA, McCoy ER (2009) Implementation and performance of storm water best management practice retrofits in Wilmington, NC. Proceedings of World Environmental and Water Resources Congress 2009: Great Rivers, Kansas City, MO; 342 5293-5300

Wyse-Mason R, Beckles D (2012) An investigation of restaurant waste oil characteristics for biodiesel production in Trinidad and Tobago. Energ Sustain Dev 16:515-519

Zargar M, Ahmadinia E, Asli H, Karim MR (2012) Investigation of the possibility of using waste cooking oil as a rejuvenating agent for aged bitumen. J Hazard Mater 233-234:254-258

Zhang H, Wang Q, Mortimer SR (2012) Waste cooking oil as an energy resource: review of Chinese policies, renew. Sustainable Energy Rev 16(7):5225-5231

Zhu J, Birgisson B, Kringos N (2014) Polymer modification of bitumen: advances and challenges. Eur Polym J 54:18-38 